\section{From Endogenous Growth Theory to Knowledge Economy Pyramid - Comparative Analysis of Knowledge as an Endogenous Factor of Development}

\section{Octavian ŞERBAN ${ }^{1}$}

${ }^{1}$ Senior researcher within Bucharest University of Economic Studies, Certified Knowledge Manager at International Knowledge Management Institute; Bucharest, Romania octavian.serban@,knomacons.ro.

\begin{abstract}
The transition from the neoclassical model with exogenous input of technological progress perspective toward $\mathrm{R} \& \mathrm{D}$ model with endogenous growth of knowledge perspective is not completed, but the premises of innovation, research, education, and entrepreneurship push the limits of labour-intensive economy to knowledge-intensive economy, where knowledge is a valuable resource for sustainable growth in the long-run and the role of Intellectual Capital is critical for increasing productivity and competitiveness. By introducing Intellectual Capital in the endogenous growth model, instead of Human Capital, we have the possibility to reflect better the difference between the market value of production and physical value. In the technological era, innovation and research are able to increase the market value comparing with the accounting value. In the 4th Industrial Revolution, this model is able to be changed dramatically if we take into account the possibility of machines to create knowledge through Artificial Intelligence, Internet of Things, new biotechnologies, new materials, and nanotechnology. For this reason, the more important action for the economic processes is to manage knowledge, starting with increased awareness, accurate measurement system, improved taxonomy, dedicated processes, and so on. In such conditions, the equation of growth theory has to be rewritten soon. The purpose of this research is not to provide a silver bullet of measurement Total Factor Productivity (TFP), but to understand better the part of productivity dedicated to the intangible and to validate this approach within the KEP model. Knowledge Economy Pyramid (KEP) is a valuable environment for incubating and accelerate knowledge in the process, as long as KEP model is creating a collaborative environment where the related stakeholders - universities, factories, technology providers, government, administration, local communities, clusters - are working together in order to achieve the objective of increasing productivity and competitiveness.
\end{abstract}

Keywords: Intellectual Capital, endogenous growth, productivity, competitiveness, Knowledge Economy.

How to cite: Şerban, O. (2020). From Endogenous Growth Theory to Knowledge Economy Pyramid - Comparative Analysis of Knowledge as an Endogenous Factor of Development. In M. W. Staniewski, V. Vasile, \& A. Grigorescu (vol. ed.), Lumen Proceedings: Vol. 14. International Conference Innovative Business Management \& Global Entrepreneurship (IBMAGE 2020) (pp.108-128). Iasi, Romania: LUMEN Publishing House.

https://doi.org/10.18662/lumproc/ibmage2020/09 


\section{Introduction - Endogenous growth theory: Romer's approach and Knowledge Economy Pyramid approach}

The founder of this theory, Paul M. Romer, is starting the rationale within the microeconomic approach. The main question is: it is capable knowledge in the process of production to increase the returns on capital? That means the higher is the input of capital in the process, the bigger the value of outputs is. From this perspective, Romer had included the Human Capital in the whole capital, as a production factor. In such conditions, what is the trigger to determine the entrepreneurs to invest in Human Capital?

The differentiation here, between the endogenous growth theory, from a microeconomic perspective and the approach of this study with a macroeconomic perspective, is to not limit the contribution of human being just to the human capital, but consider Intellectual Capital with all the components: Human Capital, Customer Capital, and Structural Capital [25].

Human Capital definition is depicting the human resources of an organization at a certain level of education, skills, training, and behaviour developed in order to create value-added. Completing the Romer's theory, knowledge methodology dedicates large resources of literature for describing Human Capital, and the most relevant for this study is knowledge retention. The layout of the global economy has changed in the last 3 or 4 decades, after the inception of the endogenous growth theory. Today, in a gig economy, human capital as a resource is very volatile, as long as the job mobility of individuals is very high. For successful entrepreneurs, knowledge as an endogenous factor of growth is no more doubt, but the challenge is to retain knowledge into the organization.

Secondly, Customer Capital, as part of Intellectual Capital, describes the ability of an organization to develop a trustworthy relationship with beneficiaries. This is the reason why, Customer Capital is called Social Capital, too. In the Digitalization Age, the relationship with customers makes the difference of being competitive or not, on the market.

Finally, Structural Capital is consisting of the organizational culture, the value of patents, the effectiveness of the decision-making process, financial connections, and so on. Basically speaking, highly valuable individuals in an organization are succeeding to increase the value of an organization as a whole. Here, we can come up with the example of Apple, Amazon, or Microsoft with over 1 trillion dollars market capitalization, but the level of the physical assets is considerably lower.

Turning back to the theoretical endogenous growth model, an entrepreneur is investing in education or research in order to obtain more benefits, tangible and sometimes intangible ones. From a practical 
perspective, this situation doesn't work in the short-run. In his microeconomic approach, Romer is starting from several assumptions: pure knowledge is non-rival, public, and non-excludable.

Knowledge is public because it could be used by anyone to achieve a specific objective and it is non-rival because the use of knowledge by someone is not diminishing the opportunity for others to use the same knowledge. Moreover, in the Knowledge Management theory is well known that knowledge is not a limited resource; it can be reused as long as that knowledge is useful for other objective or another process [8].

In the real world, the knowledge capacity to be a public good is affected by the copyright or patent, but in the long-run, most of the knowledge is public at all. In these conditions, we can talk about the availability of the knowledge and the speed to access it. So many times, to be competitive on the market means to have full access to knowledge and an optimal speed to make knowledge available.

Based on our point of view, it is important to find out if the ability to use knowledge (access and speed) could hamper the capability to use knowledge (skills and education). In other words, in a competitive world, who is in pole position: the one with the ability to use knowledge or the other with capability? The ideal model is to complete capability with the ability and this is the reason why we state that neither ability nor capability offers the maximum benefit of the knowledge. On the contrary, a model where ability and capability act in the same environment, that model is creating many opportunities for better outcomes and higher performance.

A downsizing of the competitive environment is the inclination of competitors to protect excessively the knowledge and all the efforts to be oriented to the protection of certain knowledge, which a passive approach, instead of adding value to a public knowledge, which is an active approach.

From the Knowledge Management perspective, the second one is the best because it takes into account the most important principle, sharing knowledge. We are familiar with the old fashioned concept that knowledge is power. This means the more we protect a unique knowledge, the more we gain. In a Knowledge Economy, the more a piece of knowledge is shared, the most powerful that knowledge is.

Anyway, in the endeavour to make knowledge productive in the competitive world, we have to consider both perspectives: on the one hand to offer protection to valuable knowledge in order to create an incentive for knowledge providers, and on the other hand, to offer the possibility to knowledge to be shared in such a way, people or entities with maximum capabilities to have the ability to use that knowledge. 
Upfront, Romer is considering knowledge in his model as being non-excludable, which means to give access to everyone to certain knowledge. If knowledge is non-rival and non-excludable, only then we can talk about knowledge as a public good.

From this perspective, our model Knowledge Economy Pyramid is offering a tremendous important advantage because is introducing in the equation of development by the use of knowledge, the government. One of the roles of government in the KEP model is to mitigate rivalry and excludability of knowledge in a competitive environment in such a way to put knowledge at work with a maximum of prerogatives. The lever of government in this circumstance is to offer incentives or subsidies for research and innovation providers to assure the total involvement on the one hand, and to provide maximum access on the other hand. If the role of government is harmonizing these interests quite divergent at a first stance, the synergy is created through complementarity and the returns of ability and capability to use knowledge are at the same time beneficial for the government, too.

\section{Problem Statement - Genesis of endogenous approach}

We start from the assumption of Romer for knowledge as a public good to be non-rival and non-excludable according to the concepts developed before [5]. This creates the microclimate to understand the endogenous $\mathrm{R} \& \mathrm{D}$ model. In the real world, up to a certain point, knowledge is becoming not so non-rival and not so non-excludable, too. Moreover, entering the nowadays global economy, where research and innovation are the differentiator factors for sustainable growth, knowledge is treated as a valuable resource, and then competitiveness considers the protection of knowledge as part of the game.

In the KEP model, this area of diminishing non-rivalry and nonexcludability is mitigated by the government in such a way to assure as much as possible the treatment of knowledge as a public good.

Considering the production function $(\mathrm{F})$ where technological advance which is non-rival $(A)$ and rival input $(X)$, then we have: $F(A, \lambda X)=$ $\lambda \mathrm{F}(\mathrm{A}, \mathrm{X})$.

As we already mentioned, the neoclassical model [23] considers technological progress as exogenous. Later on [3], it considers knowledge as a public good, which means non-rival and non-excludable. Then, technological progress was described as an evolutionary process based on resource sharing between $\mathrm{R} \& \mathrm{D}$ and production of tangible goods [27]. 
Technology is the result of human intervention in the process, not the result of tangible assets [16].

The non-convexity is coming in the process because the non-rival good A is an input in production. This fact reveals increasing returns considering all the inputs together. For this reason, in the equation could be introduced a replication argument because it is not necessary to have a nonrival inputs replication [21].

On the skepticism side [14], there is a few evidence that intangible cannot be measured, so that, including knowledge as endogenous factor, is a cascade of assumptions until the end of the process.

Considering the endogenous growth theory and the KEP model where knowledge is created in a collaborative environment, based on CobbDouglas production function, then we talk about Intellectual Capital (I) of a firm not only Human Capital, we have:

$$
\mathrm{Y}\left(\mathrm{I}_{\mathrm{Y}}, \mathrm{L}, \mathrm{x}\right)=\mathrm{I}_{\mathrm{Y}}^{\alpha} \mathrm{L}^{\beta} \sum_{\mathrm{i}=1} \sum_{i=1}^{\infty} \quad \mathrm{x}_{\mathrm{i}}^{1-\alpha-\beta}
$$

$\mathrm{Y}=$ output; $\mathrm{I}=$ Intellectual Capital; $\mathrm{L}=$ Labor; $\mathrm{x}=$ rival input; $\mathrm{xi}=$ number of products

Completing the theory of growth, knowledge is seen here as an endogenous factor which could be included in the production of outputs, by developing new products or by increasing the value of outputs with the contribution of Structural Capital and Customer Capital besides Human Capital.

Regarding knowledge factor through Human Capital, the protection of knowledge is increased in the global economy. In spite of this, knowledge belonging to Structural Capital and Customer Capital is difficult to be protected in an open and globalized economy. On the one hand, the ability to sell, to attract prospects, develop business relationships, and so on, there are more accessible to the public than patent and copyright, on the other hand. So, we state that knowledge is partially excludable which is beneficial in a competitive market, but the role of collaborative model is to enlarge the access to the needed knowledge, at least for the stakeholders. If one of the stakeholders is the government, then the possibility that knowledge to become entirely public is increasing.

Knowledge as an endogenous factor in this model is not belonging to the labour as intensive work of human being with all the physical capacity, but knowledge part of capital which generates increasing marginal returns. From this perspective, knowledge is a facilitator for increasing productivity, and in an open economy, is concluded in increasing competitiveness. 


\section{What is the difference between exogenous and endogenous?}

This parallel between knowledge and capital depreciation is the essence of differentiating the old school economics and the new one. In the Solow model, there is a diminishing of returns on capital during the process, even though the capital input is increasing. In Romer's model, the benefits following knowledge use are increasing the returns. Finally, this statement is the differentiation factor between endogenous growth theory and exogenous one [1].

The conclusion of this comparison is that between investment in education and accumulation of knowledge is a direct relation: the more investment in education, the bigger the accumulation of knowledge. Further on, we can say that between the accumulation of knowledge and returns on capital there is a positive correlation: the bigger the accumulation of knowledge, the higher the level of returns on capital. Closing the loop, a higher level of returns on capital contributes to stronger investment in education, and the cycle is restarting.

Extending the analysis, considering technological advance as an input of knowledge, we have here 3 theories:

- neoclassical model with technological change as an exogenous factor which generate level effect;

- modern theory with R\&D input as an endogenous factor which generates growth effect;

- the KEP model with knowledge ecosystem created which generates synergy effect;

In the R\&D model, Romer underlined the scale effect: the bigger a society/country, the more $R \& D$ resources are available, considering that a big country could afford many more people for research and innovation. From this perspective, Romer assumes that the bigger the population of a country, the higher the rate of growth.

In the global economy, with fast and direct access to the international market, this assumption is less obvious, as long as the effect of smart specialisation could be a quick response on the aggregate level of the world economy [19].

In the KEP model, the quality effect of education is a key factor for development and growth. Working in a knowledge ecosystem, knowledge is more refined and the structure of the Knowledge Triangle generates better customization of knowledge for market demand. Besides the quality of knowledge, in our model, the intensity of knowledge is higher, and the speed either. The collaboration of the relevant stakeholders in the process, determines better customization of the knowledge considering their needs, 
on the one hand, and increasing capacity for supply on the other hand, and also a higher speed of knowledge. There is no leftover knowledge produced, all the knowledge created in this environment fits perfectly the needs of the system.

A large population is worthless for the R\&D pool of researchers if the government didn't implement a strong public policy for education, research, industrialization, and innovation. The surplus of the population will follow the intensive labor approach instead of a smart one.

\section{Research Questions/Aims of the research - the layout of Knowledge Economy}

Nowadays, knowledge became more and more "tangible" [2] in the economy and the struggle of policymakers to understand the value-added of knowledge and to include the knowledge in public policies is the main asset of better adaptation to the actual status of competitiveness and perspectives to increase productivity all over the world [22].

Thinking in a neo-liberal way about the economy, that is the product depends on the money put in the process and the number of workers, it is obviously obsolete. Both of these, capital and labour are very important for economic processes, but the quantitative way of thinking is no more productive. You cannot obtain the maximum benefits of the economic processes if you don't consider knowledge as an endogenous factor of production.

More money and more workers in the era of digitalization is quite a waste of resources, instead of having a smart approach and to understand the key elements of more value-added in the production flow. Of course, any entrepreneur in a pretty decent economy is aware of the importance of value-added in the process, but doing so in a simple way is an overwhelming effort.

For this reason, we have to understand where the incentive factors of value-added are coming from and where the results of increased productivity and competitiveness are going to. The perspective of this work is the long-run approach, considering the hypothesis of knowledge contribution for smart growth as a differentiator factor for sustainable development.

As long as we start from the premises that knowledge is depending on education, research, entrepreneurship, the way of how to create, accumulate, use and transfer this knowledge is not an easy way. Moreover, the value proposition of this study is to depict the importance of these different areas of knowledge consolidation working together, in order to 
create synergy for the entire process of providing the appropriate, reliable, consistent, and efficient knowledge.

The objective of this work is not to reconsider the economic schools or thinking, but to underline the more adapted ones to the actual context. The scope is not to reinvent the wheel in the growth theory, but to understand better the ingredients of smart growth. Finally, the purpose is not to provide the silver bullet for increasing productivity and competitiveness, but to focus on the processes able to assure a better performance.

The statement is that the neo-liberal economy is ending, and remains just as a solid transition to the Knowledge Economy.

In the above-mentioned conditions, is the endogenous growth theory consistent with the current status of the economy? What about the future?

\section{Research Methods - Knowledge Economy Pyramid model}

Going to the growth theory of Paul M. Romer [20], it is assumed a long-run growth model with knowledge as an input in the production function with the role to provide marginal increases of productivity. Technological change is perceived as endogenous compared with the neoliberal one provided by the Solow model.

In our interpretation, as we already depicted in a previous work "Knowledge Economy Pyramid: Transforming Knowledge Value in Increasing Productivity and Competitiveness" [24], technological change is an accumulation and materialization of knowledge and it is depending on a serial of factors, mainly introduced by Knowledge Management.

As long as knowledge is the accelerator for increasing the valueadded in the production flow, the way how to manage this input makes the difference in the market regarding the contribution over productivity and competitiveness.

So, if you see the economy as a multitude of stakeholders' groups, working separately, sometimes compete against each other in a nonproductive way, then the technological change, specifically knowledge, could be seen as an exogenous factor for growth.

But if we consider an integrated approach, where the four pillars of Knowledge Economy are the foundation of the pyramid model with education, research, technology, administration, government, and entrepreneurship are working together in an integrative way, then knowledge, consequently technological progress, is an endogenous production factor. 
As we described in the Knowledge Economy Pyramid model (see the figure bellow), all these groups of stakeholders are working integrative through some very robust structures: Knowledge Triangle, Triple Helix, and Smart Specialisation.

By this layout built on the pillars of Knowledge Economy, the actors - university, research institutes, technology providers, local administration, government, clusters, and entrepreneurs could create an environment where the value-added of knowledge is transformed in increased productivity and competitiveness.

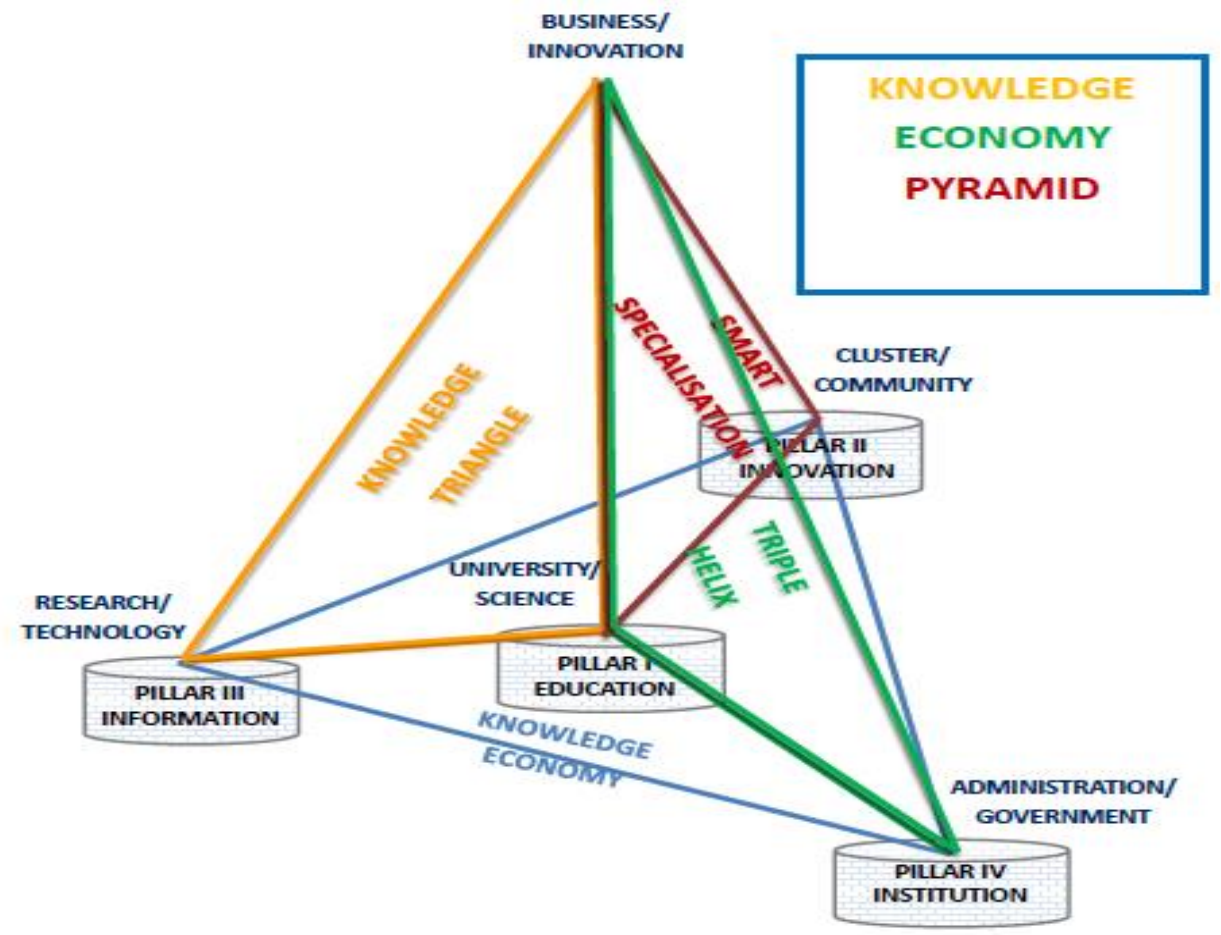

Knowledge Economy Pyramid [24]

Separately, the actors, groups of stakeholders, and even the mentioned structures are not working properly, because they are not able to cover in a separate way the actual needs of development, more complex, more flexible, customized, and very sensitive.

Knowledge Economy Pyramid is the robust response to such needs, where the knowledge ecosystems created are delivering the knowledge synergy capable to adapt better to the general economic context. Moreover, this model is capable to provide the tools for reducing the gap between the 
actual status of development and knowledge frontier in any country, depending on the level of performance in the crucial domains [24].

\section{Creating the knowledge ecosystems}

In this context, we are strongly attached by the theory of growth, where knowledge is an endogenous factor of production. In our acceptation, knowledge is not created by external providers strongly specialized as a result of the division of labour and integrated lately in the production flow as one size fits all, but knowledge is a very sensitive concept developed inside the process with the contribution of universities, entrepreneurs, ITC providers, research institutes, communities, and administration [17].

In a conservative way, knowledge is going through a channel with several stations: in university, knowledge is very theoretical oriented, sticking with fundamental research; in the economy, knowledge is very practical oriented, sticking with applied research; in administration, knowledge is very formal and rigid under the shape of the rule; lately, knowledge is turning back in the process with some more added value considering the cycle already complete.

In a knowledge-oriented economy, the stakeholders - university, factory, administration, technology providers - are working in the same environment, as a common knowledge ecosystem with a unique objective, and they have the possibility to reshape the knowledge in the process, giving more adaptation and flexibility to knowledge in order to increase the performance.

Moreover, the knowledge obtained in such an ecosystem is qualitatively superior, having already in place the contribution of all the actors at the same time and the trade-off already solved.

The proposition of the Knowledge Economy Pyramid to the research of knowledge is consisting of building the environment for creating higher value for the knowledge. This environment is a visual representation with a strong comprehension about the role of the stakeholders, their place, the connections have to be created, relationships, and synergy.

\section{Knowledge measurement}

In this context, in the place where knowledge has primary importance for the process, the contribution of knowledge to the outputs is unlimited. Considering the wide area of tacit knowledge and the importance of including it in the process, the possibility to find an increasing of the value of knowledge at the end of the process is unlimited, as we said, but is also unpredictable and very hard to measure [6].

The issue here is to succeed to follow two directions: 
- Understand better the key factors which contribute to a higher value of the knowledge;

- To compare the process with all the knowledge tools in place with the previous process or a process without knowledge methodology applied; in this circumstance, we can also compare newly obtained knowledge in the process with the process of the other economy;

In spite of this measurement progress, knowledge at this stage is very hard to measure, and this is the reason why in the processes, knowledge is considered as a residual. The scope of this work is not to come up with a more accurate measurement system for knowledge, but to understand better the entire process, the inputs, and outcomes.

\section{Knowledge process for productivity and competitiveness}

From this perspective, we can say that in any organization there are two parallel processes: an operational one, where the inputs are very tangible (capital, labour), and knowledge one, where the inputs are intangible and are consisting of the contribution of the knowledge to the capital or labour [15].

In the first process, it is already stated: the more the inputs you have, the more the outputs you produced, but only to a steady-state, after that the marginal product is diminishing rapidly. In the knowledge process, the value of knowledge is perceived as technological advancement in the conservatory neo-liberal economy and Total Factor Productivity in a modern approach. This new approach is productivity and competitiveness oriented and is focused on sustaining and improving the contribution of knowledge value added in the process.

Of course, in the real economy it is quite difficult to run two processes in the same time, one operational and the other knowledge oriented. These two have to be overlapped and running by the same operators. This study is confident with the value added in the process by the Communities of Practice, those groups of specialists at any level in an organization, dedicated to internalize knowledge in the flow of production.

In the economic theory, productivity is more related to the labour productivity, but in reality this is just a detail of the entire picture. If we consider a broader perspective, we can talk about capital productivity, factory productivity, economy productivity, processes, and so on. Productivity is a more complex concept and is not limited just to the work force [11].

What is common in the way of understanding the whole picture, it is to see knowledge in the economy as the main asset to increase productivity. In all the processes we already mentioned, the knowledge is the common factor to understand and manage productivity in the actual global context. 
Back in the 60', economists [3] consider knowledge as a stimulus for productivity as long as this is well spread around the industry and accumulated at aggregate level. Because of its nature to become public at a certain time, the returns of knowledge accumulation will be on the benefit of any particular company.

Today, waiting for knowledge to become public good is counterproductive considering the fast- moving progress and very sensitive markets on the novelty. The advantage of being first on a certain market could be translated into a huge profit. For a modern company, having the advantage of the edge is like accumulating resources for future development. More returns mean more money for innovation and research and a great opportunity to stay upfront in the industry.

\section{Critical factors for productivity and competitiveness}

Arrow's theory about the external influence of the knowledge for a specific process is changed over the years in the need for internalization of knowledge in production. Beside research and innovation benefits, in this case, we are talking about entrepreneurship. Bringing knowledge inside the process, a managed knowledge at the organizational level reveals entrepreneurial behaviour. These three elements of increasing productivity are working together: innovation, applied research and entrepreneurship.

Innovation doesn't mean discovery; innovation is much related to the market and industry (real economy) [13]. According to the Oslo Manual (2018) [18], "Innovations derive from knowledge-based activities that involve the practical application of existing or newly developed information and knowledge. Research and experimental development (R\&D), is one of a range of activities that can generate innovations, or through which useful knowledge for innovation can be acquired... An innovation is a new or improved product or process (or combination thereof) that differs significantly from the unit's previous products or processes and that has been made available to potential users (product) or brought into use by the unit (process)" [18].

For this study, it is relevant to create the space to put all these three elements together and to foster the interactions among innovation, research, and entrepreneurship. Knowledge Economy Pyramid is such a knowledge environment, where the decision-maker is part of the game along with innovation and research flow.

Back in the time, during the neo-liberal age, the approach of technological change was taken primarily as an external factor, secondly as a continuous equilibrium between market needs and knowledge providers. In 
our model, the government is deeply involved, not as a supreme authority, but as an equal partner.

Besides its active role in the knowledge ecosystem, administration/government is a facilitator for spreading the innovation and research. For this reason, investing in the human capital and research infrastructure comes first, and then the game of productivity and competitiveness is set up with a large contribution of the government [26]. This layout of collaboration between stakeholders in order to create sustainable growth for a long time has several implications over the welfare of a nation. "In countries with the lowest human capital investments today, our analysis suggests that the workforce of the future will only be one-third to one-half as productive as it could be if people enjoyed full health and received a high-quality education" [28] said Jim Yong Kim - former President of the World Bank Group.

In this context, the adaptation of the education system to the global economic reality is a must, and new curricula have to be developed in order to stimulate creativity, and innovation, entrepreneurship and knowledgeable attitude. Integration of educational programs into the industry and developing third education curricula considering real economy inputs, this is the state we all have to be work on.

The future system of education will play an important role for the new skills needed on the economy. This is the reason why the university of the future is much more oriented to provide problem-solving skills to their students instead to remain stuck-up with a conservative approach, very theoretical one.

In the same light, a modern university will provide its students the ability for teamwork. That means a totally changed attitude regarding building the behaviour of individuals regarding organizational challenges and the way they have to be addressed.

The reasoning ability is another type of skill the education has to provide during the formal learning process. In Knowledge Management is a saying that a good specialist is very good at dealing with change, but a knowledge specialist is anticipating the change. Dealing with change could be overwhelming as long as there is no control over the new context created. Anticipating the change gives the possibility to manage the new context by avoiding the threats and taking opportunities.

\section{Knowledge Economy Strategy}

Sustainable development is based in the long-run strategy and investment on education, research, and innovation. Considering education, the appropriate horizon for returns is somewhere 20 years. Here is another 
opportunity for government commitment in order to sustain this kind of investment in the long-run. This doesn't necessarily mean that everything is related to education and research is a public concern. The government has to establish a panoramic approach where the strategies for education, research, technology, business, administration, and others, are coming together in the same environment of productivity and competitiveness, complete each other, achieve complementary objectives and create sustainable development. In such conditions, above all these strategies for each field, the government has to articulate a master strategy: sustainable development strategy [9]. This kind of strategy, in the actual circumstances, could be called Knowledge Economy Strategy.

From such a perspective, we can define education productivity as gains of an individual obtained through a specific additional year of training. Of course, there are different kinds of returns, not only money as a wage; we can talk here by the possibility to increase the skills, to access private knowledge, to make the shift toward a specific job, to be able to teach others, to remain loyal to a company, etc.

In the KEP model, universities are working on the same ecosystem with companies and research institutes, according to the Knowledge Triangle Structure, in order to build a new profile of the future specialist, with solid theoretical background, verified entrepreneurial skills, and a solid orientation to innovation. From this point of view, education itself is a big contributor to increasing productivity. Investment in education is a shortcut of convergence from the development angle.

\section{Findings - The plus of Intellectual Capital}

Another advantage of introducing Intellectual Capital in the growth model, instead of Human Capital, is that we have the possibility to reflect better the difference between the market value of production and physical value. We already mentioned that in the technological era, innovation and research are able to increase the market value comparing with the accounting value.

In the $4^{\text {th }}$ Industrial Revolution, this model is able to be changed dramatically if we take into account the possibility of machines to create knowledge through Artificial Intelligence, Internet of Things, new biotechnologies, new materials, and nanotechnology [12]. For this reason, the more important for the economic processes is to manage knowledge, starting with increased awareness, accurate measurement system, improved taxonomy, dedicated processes, and so on. In such conditions, the equation of growth theory has to be rewritten soon. 
Our model, KEP, contributes to the process of internalizing knowledge in the production process and also creates the possibility to enlarge the concept of production from tangible goods to the intangibles ones.

Considering all these, a big country with a large number of individuals is a good premise for the knowledge reservoir, as long as the same percentage of researchers means much more for a large population. In spite of this quantitative advantage, we already showed that the global economy could reverse this theory or, at least, to demonstrate that for a small population, the international market is a huge opportunity to provide value for knowledge. In these conditions, growth theory assumes that not the large population is the key for competitive advantage, but a large human capital pool. In the KEP model, the structure of Smart Specialisation is decisively contributing to local innovation to become global.

We went further into this approach and had included into growth equation the concept of Intellectual Capital, in order to enlarge the picture for better fitting in the actual context of development. At this point, the most important thing is to understand that education, research, and innovation are opportunities for an economy to integrate much more human capital in the production.

From the KEP model, there are two perspectives of this opportunity:

- incubators - education and R\&D activities takes time and a lot of investments; during this phase knowledge is prepared, built, and becomes mature;

- accelerators - once the knowledge foundation is created, an appropriate environment is facilitating rapid deployment of knowledge over economy;

When in place, all these opportunities could contribute to strengthening the spillover effect of the new technologies, especially those related to IT\&C. Once the knowledge is entering in this process of the incubator, accelerator, and spillover technology, the entire process is boosting exponentially and the returns of knowledge value creation are huge, and here we have the example of strong innovators, such as Microsoft, Google, Amazon, Tesla, Apple or Samsung.

Besides spillover tools for knowledge, there are also specific techniques, and we would like to mention one of them: Communities of Practice; working in a collaborative environment with a knowledge objective mindset. 


\section{Productivity and the process, competitiveness and the market}

So far, we can conclude that, as far as knowledge, as technological advance, is an endogenous factor in the growth theory based on knowledge, on its turn economic growth is an endogenous outcome for economic processes. An endogenous outcome is easier to be absorbed in a Knowledge Economy comparing with a labour-intensive one [10].

As long as the research is directly connected to the process, innovation is filling the gap between technology or research and the market needs. At the same time, productivity, as externality of an endogenous process is more related to the process, comparing with competitiveness which is more related to the market. Combining these two statements, we can say that research and productivity consider the production processes, at the same time innovation and competitiveness consider the market arena.

In the neoclassical model we have:

$\mathrm{Y}=A K^{1-\beta}-\mathrm{L}^{\beta} ; \beta$ parameter of labour representing the share of income allocated for labour, basically the value is 0,6 ;

In the R\&D model, Romer has extracted Human Capital from labour and the equation is:

$$
\mathrm{Y}=\mathrm{AK}^{1 / 3} \mathrm{H}^{1 / 3} \mathrm{~L}^{1 / 3}
$$

In the KEP model, we use the Intellectual Capital as an expression of the Human Capital, Customer Capital, and Structural Capital, in other words, a macro-economic perspective of Romer's model. Of course, at the micro-economic level, the sense of Intellectual Capital is neglected because is related to the size of the market. The bigger the size of the market, the more important the networking, connection, ability to sell, brand, and others are. In the global market, customer relationships and networking are more obvious than national.

\section{Total Factor Productivity}

In the modern economy, technological advancement was replaced by Total Factor Productivity, that part of intangible factors that are influencing production. So, the Cobb-Douglas equation is:

$$
\mathrm{Y}=\mathrm{TFP} \mathrm{K}^{\alpha} \mathrm{L}^{1-\alpha}
$$

This factor reflects the productivity of skilled labour, we mean Intellectual Capital, but also the productivity of all the other factors which influence the output. Basically speaking, we are talking about 4 components of productivity related to capital, labour, non-IT, and TFP.

In this context, the growth rate $(\mathrm{g})$ represents the accumulation of capital and the rate of increasing TFP:

$$
\mathrm{g}=\mathrm{k}+\mathrm{tfp}
$$


If the measurement of capital accumulation is not difficult, as long as we can measure the coefficient $\alpha$, regarding the TFP, we can treat it as a residual. For example, in the OECD countries, the TFP rate is considered around $2 / 3$ of economic growth.

\section{Discussions}

Of course, there are many debates regarding the measurement of TFP. The purpose of this research was not to provide a silver bullet of measurement TFP, but to understand better the part of productivity dedicated to the intangible and to validate this approach within the KEP model.

Regarding the Intellectual Capital, it is not very difficult to measure the difference between market value and tangible assets [4], but it is quite hard to link this kind of increase of returns on capital with a particular process. In spite of this limitation of the measurement system, the benefit of accumulation still exists. At this point, until a reliable measurement methodology in place, the most important thing is to consider in this equation the entire contribution of human factor to the process.

At this stage, there are many methodologies, indices, and systems to measure knowledge and the progress is obvious. What we have to do is to keep up with the efforts to succeeding to have a more accurate measurement system for the knowledge.

By this work's approach, we are not trying to diminish the contribution of fundamental research, but the profile of this research work is oriented to the value-added of knowledge in the real economy. In other words, we are focused in the study of knowledge at work.

Comparing with capital, we cannot talk about depreciation when we talk about knowledge. The more we use a specific knowledge, the most valuable it is. At the same time, there is a contradiction between knowledge lack of depreciation and knowledge volatility [7]. Especially in the hi-tech, economy, or other smart fields, the complexity of knowledge is increasing every day. On the contrary, in construction, medicine, and others, knowledge is more stable. But, we cannot talk here about the depreciation of knowledge even if it is volatile, because the use of an old knowledge born another knowledge and the old knowledge remains at the base of a new knowledge. For physical assets, once a piece of equipment is depreciated, it is replaced by the entirely new one. 


\section{Conclusions}

Including the Intellectual Capital in the production function as an endogenous factor is more relevant for sustainable development because is considering the entire value of knowledge in the process. In spite of many advanced measurement tools for knowledge, there is no accurate system in place capable to replace the current approach which considers the contribution of knowledge as a residual.

Though, the importance of knowledge is much more considered in the process and the value-added of education, research, innovation, and entrepreneurship are obvious with a direct impact on economic growth.

According to this impact, Knowledge Economy Pyramid is a valuable environment for incubating and accelerate knowledge in the process, as long as KEP model is creating a collaborative environment where the related stakeholders - universities, factories, technology providers, government, administration, local communities, clusters - are working together in order to achieve the objective of increasing productivity and competitiveness.

\section{Acknowledgement:}

This paper was co-financed from the Human Capital Operational Program 2014-2020, project number POCU / 380/6/13/125245 no. 36482 / 23.05.2019 "Excellence in interdisciplinary $\mathrm{PhD}$ and post-PhD research, career alternatives through entrepreneurial initiative (EXCIA)", coordinator The Bucharest University of Economic Studies"

\section{References}

[1] Acemoglu D. Introduction to Modern Economic Growth. USA: Princeton University Press; 2009. 1008 p.

[2] Abdih Y, Joutz F. Relating the Knowledge Production Function to Total Factor Productivity: An Endogenous Growth Puzzle. International Monetary Fund [Internet]. 2005 Apr 1, [cited 2020 Aug 18];53(2):242-271. Available from:

https://www.imf.org/en/Publications/WP/Issues/2016/12/31/Relatingthe-Knowledge-Production-Function-to-Total-Factor-Productivity-AnEndogenous-Growth-18129

[3] Arrow KJ. Economic Welfare and the Allocation of Resources to Invention. In: Universities-National Bureau Committee for Economic Research, Committee on Economic Growth of the Social Science Research Council, 
editor. The Rate and Direction of Inventive Activity: Economic and Social Factors. New Jersey: Princeton University Press; 1962, pp. 609-626.

[4] Burgess TF, Heap J. Editorial. International Journal of Productivity and Performance Management [Internet]. 2015 Apr 13 [cited 2020 Aug 18];64(4). Available from: https://doi.org/10.1108/IJPPM-02-2015-0030

[5] Cornes R, Sandler T. The theory of externalities, public goods, and club goods. New York: Cambridge University Press; 1986. 315 p.

[6] Daum JH. Intangible Assets and Value Creation. USA: Wiley; 2002. 444 p.

[7] Esposti R, Pierani P. Building the Knowledge Stock: Lags, Depreciation, and Uncertainty in R\&D Investment and Link with Productivity Growth. Journal of Productivity Analysis [Internet]. 2003 Jan [cited 2020 Oct 5];19:33-58. Available from: https://doi.org/10.1023/A:1021818019626

[8] European Commission. Metrics for Knowledge Transfer from Public Research Organisations in Europe. [Internet] Luxembourg: Publications Office of the European Union; 2009 [cited 2020 Oct 5]. Available from: https://op.europa.eu/en/publication-detail/-/publication/d0dbd13d-6b284398-896b-0fe9cf0ed2cb

[9] European Commission. Sustainable development in the European Union. [Internet] Luxembourg: Publications Office of the European Union; 2020 [cited 2020 Oct 5]. Available from: https://ec.europa.eu/eurostat/statisticsexplained/index.php/Sustainable development in the European Union

[10] European Commission. EU Productivity and Competitiveness: An Industry Perspective-Can Europe Resume the Catching-up Process? [Internet] Luxembourg: Office for Official Publications of the European Communities; 2003 [cited 2020 Oct 5]. Available from: https://ec.europa.eu/digital-singlemarket/en/news/eu-productivity-and-competitiveness-industry-perspectivecan-europe-resume-catching-process-pdf

[11] Fraumeni B. Measuring Economic Growth and Productivity. London: Academic Press; 2019. 554 p.

[12] Johannessen JA. The Emergence of the Fourth Industrial Revolution: An Historical Introduction to Knowledge Management and the Innovation Economy. UK: Emerald Publishing Limited; 2019. 144 p.

[13] Kimmo H, Kimmo V, Merisalo M. Governing the Knowledge Economy Ecosystem. In: Kimmo H, Ilari L, Piirainen KA, Salminen V, White J, editors. Finland as a Knowledge Economy 2.0: Lessons on Policies and Governance. World Bank Group [Internet]. 2014 Apr [cited 2020 Oct 5]. pp. 77 - 96. Available from: https://doi.org/10.1596/978-1-4648-0194-5 ch5

[14] Krugman P. Studyguide for Microeconomics. USA: Publisher Cram 101; 2013 Jan 2. 
[15] Laperche B. The Firm, Knowledge and Capital: Toward the Definition of Knowledge Capital. In: Laperche B, editor. Enterprise Knowledge Capital [nternet]. USA: Willey; 2017 [cited 2020 Oct 5]. Volume 13. pp.1-60. Available from: https://doi.org/10.1002/9781119478393.ch1

[16] Lucas RE. On the Mechanics of Economic Development. Journal of Monetary Economics [Internet]. 1988 [cited 2020 Oct 5];22:3-42. Available from: https://doi.org/10.1016/0304-3932(88)90168-7

[17] Mckeown M. The Truth About Innovation. Canada: Pearson Education; 2008.

[18] OECD/Eurostat. Oslo Manual 2018. Oslo Manual 2018: Guidelines for Collecting, Reporting and Using Data on Innovation, 4th Edition, The Measurement of Scientific, Technological and Innovation Activities. [Internet] Paris/Eurostat, Luxembourg: OECD Publishing; 2019 [cited 2020 Jul 11]. Available from: https://doi.org/10.1787/9789264304604-en

[19] Radosevic S, Curaj A, Gheorghiu R, Andreescu L, Wade I, editors. Advances in the Theory and Practice of Smart Specialization. London: Academic Press; 2017. 394 p.

[20] Romer PM. Increasing Returns and Long-Run Growth. Journal of Political Economy [Internet]. 1986 [cited 2020 Jul 11];94(5):1002-1037. Available from: http://www.jstor.org/stable/1833190

[21] Romer PM. Endogenous Technological Change. Journal of Political Economy [Internet]. 1990 [cited 2020 Oct 3];98(5):S71-S102. Available from: http://www.jstor.org/stable/2937632

[22] Rooney D, Hearn G., Mandeville T, Joseph R. Public Policy in KnowledgeBased Economies: Foundations and Frameworks (New Horizons in Public Policy Series). UK: Edward Elgar Pub; 2003. 192 p.

[23] Solow RM. A Contribution to the Theory of Economic Growth. The Quarterly Journal of Economics [Internet]. 1956 Feb [cited 2020 Oct 3];70(1):65-94. Available from: https://www.jstor.org/stable/1884513

[24] Şerban O. Knowledge Economy Pyramid: Transforming Knowledge Value in Increasing Productivity and Competitiveness. South Korea: Korea Institute for International Economic Policy; 2018.

[25] Teece DJ. Managing Intellectual Capital: Organizational, Strategic, and Policy Dimensions. Oxford: Oxford University Press. 2002.

[26] Thomas-Gregory A, Mercer J. Investing in our education? Leading, learning, researching and the doctorate. UK: Emerald [Internet]; 2014 [cited 2020 Oct]. Available from: https://doi.org/10.1108/S1479-362820140000013017 
[27] Uzawa F. Optimum Technical Change in An Aggregative Model of Economic Growth. International Economic Review [Internet]. 1965 [cited 2020 Oct 3];6(1):18-31. Available from: https://doi.org/10.2307/2525621

[28] Stromquist NP. World Development Report 2019: The changing nature of work. International Review of Education [Internet]. 2019 [cited 2020 September 7];65:321-329. Available from: https://doi.org/10.1007/s11159_ $\underline{019-09762-9}$ 